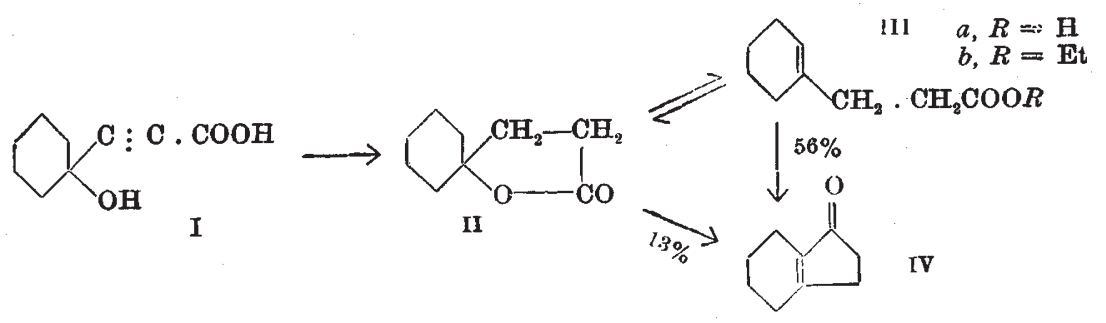

the corresponding hydride or deuteride, and as a measure of the increasing stability of di-atoms in a given period with increasing group num. ber : for example, in the $\mathrm{KH}$ period from $\mathrm{Li}^{+} \mathrm{H}^{-}$to $\mathrm{F}^{-} \mathrm{H}^{+}$.

An interesting and apparently general principle has emerged from this work, to the effect that stability in.

Eistert homologation of cyclohexenylacetic acid. Ring closure of $\beta$-(cyclohexenyl)propionic acid (III $a$ ) to $4: 5: 6: 7$-tetrahydroindanone with acetic anhydridezinc chloride proceeded in 56 per cent yield.

\begin{tabular}{|c|c|c|}
\hline Substance & Conditions & Products \\
\hline $\begin{array}{c}\gamma \text {-(cyclohexyl) } \\
\text { spirobutyro- } \\
\text { lactone (II) }\end{array}$ & $\begin{array}{l}\text { Potass. bisulphate, } \\
200^{\circ} \mathrm{C} ., 45 \text { min. } \\
\text { Anhydrous oxalic } \\
\text { acid, 200 } \mathrm{C} \text {. } 1 \mathrm{hr} \text {. } \\
\text { Reagent } A^{4} 4 \mathrm{hr} \text {. } \\
\text { " } A^{48}, "\end{array}$ & $\begin{array}{l}14 \% \text { acid } 80 \% \text { lactone } \\
16 \% \text { acid } 80 \% \text { lactone } \\
2 \% \text { acid } 94 \% \text { lactone } \\
2 \% \text { acid } 93 \% \text { lactone }\end{array}$ \\
\hline $\begin{array}{l}\beta \text {-(cyclohexenyl) } \\
\text { propionic acid } \\
\text { (III } a \text { ) }\end{array}$ & $\begin{array}{c}\text { Reagent } A^{4} 4 \mathrm{hr} . \\
\quad, \quad A^{\triangleleft} 8 \text { " }\end{array}$ & $\begin{array}{l}30 \% \text { acid } 65 \% \text { lactone } \\
10 \% \text { acid } 82 \% \text { lactone }\end{array}$ \\
\hline
\end{tabular}

The position of equilibrium of the lacto-enoic tautomerism II $\rightleftharpoons$ III $a$ has also been established under certain conditions; our results agree with those of Johnson. The above series of reactions is being examined with substituted cyclohexanones, and the results will be communicated elsewhere in due course.

One of us (D. W. M.) wishes to thank the University of London for the award of an I.C.I. Fellowship, during the tenure of which the above work was carried out.

W. H. LINNELL

D. W. Mathieson

School of Pharmacy, University of London,

17 Bloomsbury Square, London, W.C.1.

1 Johnson and Hunt, J. Amer. Chem. Soc., 72, 935 (1950).

Haynes and Jones, J. Chem. Soc., 505 (1946). 'Cason; Adams, Bennett and Register, J. Amer. Chem. Soc, 66, 1764

- Johnson, Peterson and Sneider, J. Amer. Chem. Soc., 69, 74 (1947).

\section{Mean Restoring Forces of Hydride Di-Atoms and their Positive lons}

I HAVE recently published the periodic table of deuteride di-atoms and their positive ions, thus completing a programme initiated by the periodic classification of the elements ${ }^{2}$, and of non-hydride ${ }^{3}$ and hydride 4 di-atoms according to electron configurations. In a forthcoming communication ${ }^{5}$, I propose to examine in the light of these tables a suggestion made by Dadieu and Kohlrausch that the 'mean restoring force' of a linkage may be used as a measure of bonding strength. The authors found that for $\mathrm{C}-\mathrm{C}, \mathrm{C}=\mathrm{C}$ and $\mathrm{C} \equiv \mathrm{C}$ linkages the mean restoring forces were closely in the ratio $1: 2: 3$.

The mean restoring force of a di-atom is messured by $K=1,878 \sqrt{\mu \omega_{\theta}{ }^{3}}$, whereas the bond constant is $k_{e}=3.550 \times 10^{22} \mu \omega_{e}^{2}$ (c.G.s. units). It is thus found that $K$ generally changes from one case to another in the same sense as $k_{e}$ and $D_{e}$ (dissociation energy), and is a periodic function for hydrides. I have indicated that $K$ appears to be a suitable magnitude for comparing changes in binding force in considering the effects of formation of singly charged positiveions from creases on ionization when the hydrogen atom lies at the negative end of the dipole, that is, for hydrides near the beginning of a period, and decreases when it is at the positive end, for hydrides of elements on the right of the periodic table. In the, middle groups, the changes in stability are correspondingly small. The positive and negative effects are apparently greatest in the $\mathrm{KH}$ period in Groups II ( $\mathrm{LiH}$ ) and VIII (FH) respectively, and least in Group V (CH). They also increase from one period to the next in the same group. The accompanying table shows the percentage change in mean restoring force of hydrides $A H$ on ionization for cases where data are available.

\begin{tabular}{|c|c|c|c|c|c|}
\hline \multirow{2}{*}{ Period } & \multicolumn{5}{|c|}{ Group number and atom $A$} \\
\hline & II & IIII & IV & VII & VIII \\
\hline $\begin{array}{l}\text { HH } \\
\text { KH } \\
\text { LH } \\
\text { MH } \\
\text { NH } \\
\text { OH }\end{array}$ & H $-62 \cdot 3$ & $\begin{array}{l}\mathrm{Be}+13 \cdot 2 \\
\mathrm{Mg}+21 \cdot 1 \\
\mathrm{Zn}+30 \cdot 1 \\
\mathrm{Cd}+45 \cdot 9 \\
\mathrm{Hg}+77 \cdot 6\end{array}$ & $\left(\begin{array}{c}\mathrm{B}+4 \cdot 5 \\
(\mathrm{Al}-6 \cdot 7)\end{array}\right.$ & $0-29 \cdot 5$ & Cl $-15 \cdot 3$ \\
\hline
\end{tabular}

In an earlier communication, Walsh ${ }^{7}$ noticed the drop in binding strength of $\mathrm{OH}$ and $\mathrm{BrH}$ on ionization, as judged by changes in internuclear distance. This observation is now brought into line with a general scheme. The large drop in stability in passing from $\mathrm{HH} \rightarrow \mathrm{HH}^{+}$is doubtless connected with the setting up of a one-electron linkage. The other changes are satisfactorily explained by Walsh's polarity theory, to the effect that increasing stability accompanies decreasing polarity, and vice versa. The theory must be confined to changes of polarity of the same two atoms involved in a linkage. It is not applicable to account for changes of stability from CH to FH, where both stability and polarity increase. These changes may be referred instead to the increasing positivity of the hydrogen atom.

The small changes in $K$ for $\mathrm{BH}$ and AlH shown in the above table suggest a still smaller value for $\mathrm{CH} \rightarrow \mathrm{CH}+$. In the middle of a period, ionization máy involve a slightly polar bond reversing its dipole, with only a small attendant change in stability. This possibly also happens in the $\mathrm{CH}$ bond from $\mathrm{CH}_{4}$ to $\mathrm{C}_{2} \mathrm{H}_{4}$, where only a small change in internuclear distance $\left(1.094\right.$ to circa $1.087 \mathrm{~A}$.) occurs ${ }^{2,8}$. A fall in internuclear distance is linked with rising mean restoring force and increasing stability.

Department of Inorganic and

$$
\text { C. H. Douglas Clark }
$$

Physical Chemistry,

University of Leeds. Feb. 22.

${ }^{1}$ Clark, C. H. Douglas, Proc. Leeds Phil. Soc., 5, 244 (1949).

2 Idem, ibid., 2, 225 (1931); 3, 281 (1936).

Idem, ibid., 2, 502 (1933); Trans. Frarad. Soc., 31, 1017 (1935).

-Idism, Proc. Leeds Phil. Soc., 3, 218 (1936).

- Idem, ibid. (in the press).

- Dadieu, A., and Kohlrausch, K. W. F., J. Opt. Soc. Amer., 21, 286 (1931).

Walsh, A. D., Trans. Farad. Soc., 43, 60 (1947).

I Idem, J. Amer. Chem. Soc., 68, 2408 (1946). 